\title{
Gene variants and educational attainment in cannabis use: mediating role of DNA methylation
}

\author{
Maria Carla Gerra', Subramaniam Jayanthi', Matteo Manfredini', Donna Walther², Jennifer Schroeder,
} Karran A. Phillips ${ }^{3}$, Jean Lud Cadet $^{2}$ and Claudia Donnini ${ }^{1}$

\begin{abstract}
Genetic and sociodemographic risk factors potentially associated with cannabis use (CU) were investigated in 40 cannabis users and 96 control subjects. DNA methylation analyses were also performed to explore the possibility of epigenetic changes related to CU. We conducted a candidate gene association study that included variants involved in the dopaminergic (ANKK1, NCAM1 genes) and endocannabinoid (CNR1, CNR2 gene) pathways. Sociodemographic data included gender, marital status, level of education, and body mass index. We used MeDIP-qPCR to test whether variations in DNA methylation might be associated with CU. We found a significant association between SNP rs 1049353 of CNR1 gene $(p=0.01)$ and CU. Differences were also observed related to rs2501431 of CNR2 gene $(p=$ 0.058). A higher education level appears to decrease the risk of CU. Interestingly, females were less likely to use cannabis than males. There was a significantly higher level of DNA methylation in cannabis users compared to controls in two of the genes tested: hypermethylation at exon 8 of DRD2 gene $(p=0.034)$ and at the $C p G$-rich region in the NCAM1 gene $(p=0.0004)$. Both genetic variants and educational attainment were also related to CU. The higher rate of DNA methylation, evidenced among cannabis users, may be either a marker of CU or a consequence of long-term exposure to cannabis. The identified genetic variants and the differentially methylated regions may represent biomarkers and/or potential targets for designs of pharmacological therapeutic agents. Our observations also suggest that educational programs may be useful strategies for $\mathrm{CU}$ prevention.
\end{abstract}

\section{Introduction}

Marijuana is the most common drug used illicitly throughout the world. Approximately $9 \%$ of those exposed to cannabis become addicted (cannabis use disorder, DSM-5). The number increases to $16 \%$ when cannabis use $(\mathrm{CU})$ is initiated during adolescence and to $50 \%$ when cannabis is used daily ${ }^{1}$. Because of the gateway hypothesis of early $\mathrm{CU}^{2}$ and because of potential negative effects of the $\mathrm{drug}^{3}$, genetic risk factors for

\footnotetext{
Correspondence: Jean Lud Cadet (jcadet@intra.nida.nih.gov)

${ }^{1}$ Department of Chemistry, Life Science and Environmental Sustainability,

University of Parma, Parma, Italy

${ }^{2}$ Molecular Neuropsychiatry Research Branch, NIDA Intramural Research

Program, Baltimore, MD, USA

Full list of author information is available at the end of the article
}

CU have been investigated using a diversity of methods. Twin studies have suggested that genetic markers may explain about $50 \%$ of the variance in $\mathrm{CU}$ disorders ${ }^{4-7}$. Association studies have also provided evidence of genetic risks that include differential changes at Taq1A allele (rs1800497, ANKK1) that influences the function of dopamine receptors ${ }^{8}$. In addition, changes at rs1049353, rs806380, rs2180619, rs806379, rs12720071, rs2023239 and the haplotype rs6454674-rs806380-rs806377rs1049353 in the cannabinoid receptor 1 gene (CNR1) and at rs2501431 in the cannabinoid receptor 2 gene (CNR2) were found to be associated with working memory dysfunction, enhanced impulsivity, neurocognitive impairments, anxiety disorder, and depression in cannabis users $^{9-13}$. 
Interestingly, genome-wide association studies of cannabis users and dependent individuals have also identified several genetic variants that are known to play a role in neurogenesis and dopaminergic neurotransmission. These include ANKFN1, RP11-206 M11.7, SLC35G1, CSMD1, NCAM1, CADM2, SCOC and KCNT2 ${ }^{14-16}$. Whole genome sequencing approaches have also documented variations involved in the regulation of MEF2$B$ and $P C C B$ genes expression ${ }^{17}$. Moreover, a gene cluster located on chromosome 17q24 [c17orf58, BPTF, PPM1D] was previously reported to be associated with cannabis use disorders (CUD) diagnosed by DSM- $5{ }^{18}$.

Several investigators have sought to identify environmental factors and clarify how their interactions with inherited familial risk conditions and related gene variants might impact susceptibility to cannabis abuse. Traumatic and negative life events, including poor parental care, reduced family bonding, childhood maltreatment, physical and sexual abuse, exposure to community violence, low level of school engagement, as well as school dropouts appear to play important roles in the initiation and persistence of $\mathrm{CU}^{19-24}$. Nevertheless, the mechanisms of interactions between these factors and their relationships to $\mathrm{CU}$ remain to be clarified.

The picture is rendered more complicated by epigenetic factors that might also trigger the initiation and/or maintenance of $\mathrm{CUD}^{25-30}$. Specifically, modifications in DNA methylation have been reported in cannabis users, in tetrahydrocannabinol (THC)-dependent subjects, and in a rat model of prenatal THC exposure to $\mathrm{CB} 1$ and $\mathrm{CB} 2{ }^{25,29}$. These included DNA modifications in catechol$O$-methyltransferase $(C O M T)$ gene $^{26}$ and in PACSIN1, a kinase involved in neuron morphogenesis and neurodevelopmental processes ${ }^{30}$. Interestingly, a significant relationship between DNA sequence variants and DNA methylation has also been established ${ }^{26,31,32}$.

Despite the reported association between genetic risks and $\mathrm{CU}$, more remains to be done to further clarify the role that these genetic changes might play in diverse populations. Therefore, the major aim of our study was to identify risk factors that can trigger or exacerbate the clinical course of CU. Towards that end, we sought to investigate the potential role of gene variants affecting dopamine and cannabinoid receptors function, SNP Taq1A (ANKK1) and the SNP rs1049353 (CNR1) in CU. Second, we also studied interactions of these variants with sociodemographic measures including body mass index (BMI), gender, marital status, and levels of education. Third, we sought to discover if changes in DNA methylation might also play a role in CU.

\section{Materials and methods Subjects}

A total of 136 subjects (Table 1), 40 cannabis users (30 males and 10 females) and 96 control subjects (38 males
Table 1 Socio-demographic data of samples collected (96 CTRLs subjects and $40 \mathrm{MJ}$ users)

\begin{tabular}{|c|c|c|c|c|}
\hline & \multicolumn{2}{|c|}{$\begin{array}{l}\text { Controls } \\
(n=96)\end{array}$} & \multicolumn{2}{|c|}{$\begin{array}{l}\text { MJ users } \\
(n=40)\end{array}$} \\
\hline & $n$ & $\%$ & $n$ & $\%$ \\
\hline \multicolumn{5}{|l|}{ Gender } \\
\hline Male & 38 & $39.58 \%$ & 30 & $75.00 \%$ \\
\hline Female & 58 & $60.42 \%$ & 10 & $25.00 \%$ \\
\hline \multicolumn{5}{|l|}{ Marital status } \\
\hline Not married & 84 & $87.50 \%$ & 38 & $95.00 \%$ \\
\hline Married & 12 & $12.50 \%$ & 2 & $5.00 \%$ \\
\hline \multicolumn{5}{|l|}{ Level of education } \\
\hline 1 = some high school/GED & 12 & $12.50 \%$ & 12 & $30.00 \%$ \\
\hline $2=$ H.S. diploma & 24 & $25.00 \%$ & 10 & $25.00 \%$ \\
\hline $3=$ some college & 33 & $34.38 \%$ & 16 & $40.00 \%$ \\
\hline $4=$ college graduate $/$ Masters / Ph.D. & 27 & $28.13 \%$ & 2 & $5.00 \%$ \\
\hline \multicolumn{5}{|l|}{ BMI } \\
\hline$<25$ & 36 & $39.56 \%$ & 18 & $48.65 \%$ \\
\hline$\geq 25$ & 55 & $60.44 \%$ & 19 & $51.35 \%$ \\
\hline \multicolumn{5}{|l|}{ Ethnicity } \\
\hline African American & 63 & $66.32 \%$ & 34 & $87.18 \%$ \\
\hline Asian & 2 & $2.11 \%$ & 0 & $0.00 \%$ \\
\hline European American & 24 & $25.26 \%$ & 3 & $7.69 \%$ \\
\hline More than one race & 5 & $5.26 \%$ & 2 & $5.13 \%$ \\
\hline Native Hawaiian or other Pacific & 1 & $1.05 \%$ & 0 & $0.00 \%$ \\
\hline Missing & 1 & & 1 & \\
\hline
\end{tabular}

and 58 females), aged 18-60 years, were selected among samples collected and stored previously at the Intramural Research Program (IRP) of the National Institute of Drug Abuse (NIDA), project \#12-DA-N472, NIDA, IRP (Health Outcomes by Neighborhood (HON)-Baltimore). These subjects were recruited among people who live in Baltimore City or one of the surrounding areas. Based on frequency of use, the cannabis participants were moderate to heavy users ${ }^{33}$, with no other drug use or alcohol abuse (total $n=40$; moderate, $n=20$ and heavy, $n=20$ ). Ninety-six (96) unrelated healthy individuals who live in the same geographic area and who have never smoked cannabis served as control participants. The study was approved by the NIDA Addiction IRB. Written informed consent was obtained from all participants. The subjects were reimbursed for their time.

Exclusion criteria included inability to sign informed consent and age $<18$ years old. Participants in the present study were excluded for other illicit drugs or alcohol. In 
addition to self-report, the use or abuse of other illicit substances was ruled out by obtaining observed urines that were negative for methamphetamine, 3,4-methylenedioxymethamphetamine, benzodiazepines, cocaine metabolites, methadone, oxycodone, phencyclidine, buprenorphine, and morphine. The participants were screened for prevalence of anxiety disorder (measured by Brief Anxiety Scale (BAS)) and PTSD disorder (measured by PTSD Checklist-Civilian Version (PCL-C)). Only four participants were affected by possible co-occurring anxiety and PTSD disorder. The number was too low to allow another statistical analysis.

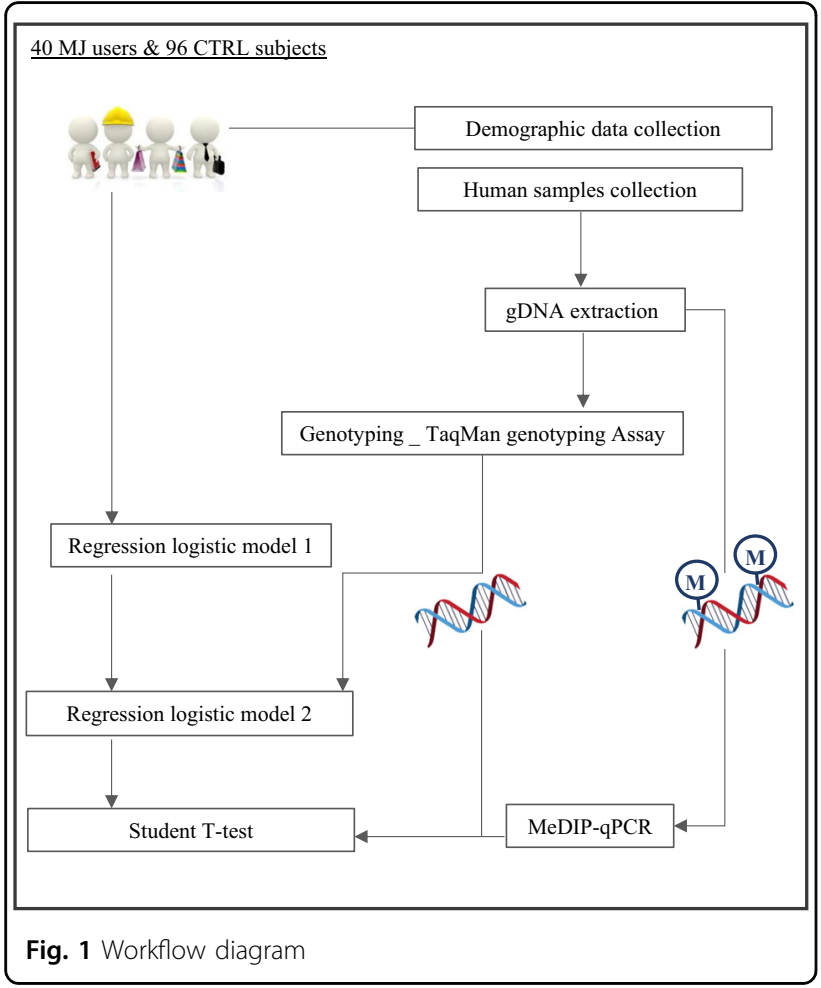

\section{Design}

The study follows the workflow showed in Fig. 1.

\section{Sociodemographic measures}

Sociodemographic data were collected for each subject (see Table 1). A semi-structured questionnaire was utilized to collect socio-demographic data concerning gender, marital status, educational attainment, BMI, and ethnicity.

\section{Sample collection and DNA extraction}

Peripheral whole blood was previously collected from participants via venipuncture and $5 \mathrm{~mL}$, maintained at $-80^{\circ} \mathrm{C}$, were used in the present study (see Supplementary material for preparation of blood samples). DNA extraction was carried out using the QIAamp DNA Blood Midi/Maxi Kit (Spin Protocol, Qiagen). Aliquots of the genomic DNA extracted were used for both genotyping and DNA methylation analysis.

\section{Genotyping}

The polymorphisms related to the genes listed in Table 2A were genotyped in cannabis users and controls. Ten nanograms of genomic DNA were processed with TaqMan Genotyping Assays (Thermo Fisher) for the identification of allelic variants (see Supplementary material for detailed procedure).

\section{DNA methylation analysis}

DNA methylation status was analyzed in seven sites, listed in Fig. 2a. These were in regions of ANNK1, CNR1, and in two genes that belong to the same cluster of $A N K K 1$ on chromosome 11, DRD2 and NCAM1 genes. The primer sequences were designed to include sites as close as possible to the polymorphic SNP Taq1A and to the SNP rs1049353 or to the transcription start site (TSS) including $\mathrm{CPG}$ regions and intron-exon junctions.

To quantify DNA methylation in specific sites of genes (listed in Fig. 2a) involved in the neurobiology of CUD,

Table 2A List of candidate genes and analyzed polymorphisms

\begin{tabular}{|c|c|c|c|c|c|}
\hline Gene & SNP & DNA sequence variation & Position & Functional consequence & Global MAF \\
\hline ANKK1 & rs1800497 & $\mathrm{C} / \mathrm{T}(\mathrm{REV})$ & 11:113400106 & missense: Glu $\Rightarrow$ Lys & $A=0.3257 / 1631$ \\
\hline CNR1 & rs1049353 & $\mathrm{A} / \mathrm{G}(\mathrm{REV})$ & 6:88143916 & synonymous codon: $\mathrm{Thr} \Rightarrow \mathrm{Thr}$ & $\mathrm{T}=0.1294 / 648$ \\
\hline CNR1 & rs2180619 & $\mathrm{A} / \mathrm{G}(\mathrm{FWD})$ & $6: 88168233$ & upstream variant $2 \mathrm{~KB}$ & $G=0.4685 / 2346$ \\
\hline CNR1 & rs806379 & $\mathrm{A} / \mathrm{T}(\mathrm{FWD})$ & $6: 88151548$ & intron variant, upstream variant $2 \mathrm{~KB}$ & $\mathrm{~T}=0.3952 / 1979$ \\
\hline CNR1 & rs6454674 & $\mathrm{G} / \mathrm{T}(\mathrm{FWD})$ & $6: 88163211$ & intron variant & $G=0.3141 / 1573$ \\
\hline CNR1 & rs12720071 & $\mathrm{A} / \mathrm{G}(\mathrm{REV})$ & $6: 88141462$ & UTR variant $3^{\prime}$ & $C=0.0899 / 450$ \\
\hline CNR1 & rs2023239 & $\mathrm{C} / \mathrm{T}(\mathrm{FWD})$ & $6: 88150763$ & intron variant, upstream variant $2 \mathrm{~KB}$ & $C=0.1779 / 891$ \\
\hline CNR2 & rs2501431 & $\mathrm{A} / \mathrm{G}(\mathrm{FWD})$ & $1: 23875153$ & synonymous codon: Gly $\Rightarrow$ Gly & $G=0.3466 / 1736$ \\
\hline
\end{tabular}


Table 2B Genotype and allele frequencies

\begin{tabular}{|c|c|c|c|c|}
\hline $\begin{array}{l}\text { SNP ID } \\
\text { (gene) }\end{array}$ & $\begin{array}{l}\text { Genotypes } \\
\text { and alleles }\end{array}$ & $\begin{array}{l}\text { Subjects } \\
\text { CTRLs }\end{array}$ & MJ users & $\begin{array}{l}\text { Fisher's } \\
\text { exact test }\end{array}$ \\
\hline \multirow{6}{*}{$\begin{array}{l}\text { rs1800497 } \\
\text { (ANKK1) }\end{array}$} & $\mathrm{CC}$ & $50,00 \%$ & $51.28 \%$ & 0.76 \\
\hline & & & & \\
\hline & $\Pi$ & $9.38 \%$ & $12.82 \%$ & \\
\hline & $C T$ & $40.63 \%$ & $35.90 \%$ & \\
\hline & C allele & $87.10 \%$ & $76.63 \%$ & 0.88 \\
\hline & T allele & $12.90 \%$ & $23.37 \%$ & \\
\hline \multirow{5}{*}{$\begin{array}{l}\text { rs1049353 } \\
\text { (CNR1) }\end{array}$} & GG & $78.13 \%$ & $97.44 \%$ & 0.01 \\
\hline & $\mathrm{AA}$ & $4.17 \%$ & $0.00 \%$ & \\
\hline & GA & $17.71 \%$ & $2.56 \%$ & \\
\hline & G & $86.98 \%$ & $98.72 \%$ & 0.002 \\
\hline & A & $13.02 \%$ & $1.28 \%$ & \\
\hline \multirow{5}{*}{$\begin{array}{l}\text { rs2180619 } \\
\text { (CNR1) }\end{array}$} & $\mathrm{AA}$ & $21.74 \%$ & $23.68 \%$ & 0.9 \\
\hline & GG & $34.78 \%$ & $36.84 \%$ & \\
\hline & $A G$ & $43.48 \%$ & $39.47 \%$ & \\
\hline & A allele & $43.48 \%$ & $43.42 \%$ & 1 \\
\hline & G allele & $56.52 \%$ & $56.58 \%$ & \\
\hline \multirow{6}{*}{$\begin{array}{l}\text { rs806379 } \\
\text { (CNR1) }\end{array}$} & $\mathrm{AA}$ & $19.79 \%$ & $17.95 \%$ & 0.62 \\
\hline & & & & \\
\hline & $\pi$ & $25.00 \%$ & $33.33 \%$ & \\
\hline & AT & $55.21 \%$ & $48.72 \%$ & \\
\hline & A allele & $47.40 \%$ & $42.31 \%$ & 0.5 \\
\hline & T allele & $52.60 \%$ & $57.69 \%$ & \\
\hline \multirow{5}{*}{$\begin{array}{l}\text { rs6454674 } \\
\text { (CNR1) }\end{array}$} & GG & $12.77 \%$ & $7.50 \%$ & 0.21 \\
\hline & $\pi$ & $36.17 \%$ & $52.50 \%$ & \\
\hline & GT & $51.06 \%$ & $40.00 \%$ & \\
\hline & G allele & $38.30 \%$ & $27.50 \%$ & 0.09 \\
\hline & T allele & $61.70 \%$ & $72.50 \%$ & \\
\hline \multirow{5}{*}{$\begin{array}{l}\text { rs12720071 } \\
\text { (CNR1) }\end{array}$} & CC & $21.88 \%$ & $20.51 \%$ & 1 \\
\hline & $\pi$ & $0.00 \%$ & $0.00 \%$ & \\
\hline & $\mathrm{TC}$ & $78.13 \%$ & $79.49 \%$ & \\
\hline & C allele & $60.94 \%$ & $60.26 \%$ & 1 \\
\hline & T allele & $39.06 \%$ & $39.74 \%$ & \\
\hline \multirow{3}{*}{$\begin{array}{l}\text { rs2023239 } \\
\text { (CNR1) }\end{array}$} & CC & $10.42 \%$ & $12.50 \%$ & 0.47 \\
\hline & $\pi$ & $48.96 \%$ & $37.50 \%$ & \\
\hline & $\mathrm{TC}$ & $40.63 \%$ & $50.00 \%$ & \\
\hline
\end{tabular}

Table 2B continued

\begin{tabular}{lllll}
\hline $\begin{array}{l}\text { SNP ID } \\
\text { (gene) }\end{array}$ & $\begin{array}{l}\text { Genotypes } \\
\text { and alleles }\end{array}$ & $\begin{array}{l}\text { Subjects } \\
\text { CTRLs }\end{array}$ & MJ users & $\begin{array}{l}\text { Fisher's } \\
\text { exact test }\end{array}$ \\
\hline & C allele & $30.73 \%$ & $37.50 \%$ & 0.32 \\
& T allele & $69.27 \%$ & $62.50 \%$ & \\
rs2501431 & AA & $47.37 \%$ & $58.97 \%$ & 0.058 \\
(CNR2) & & & & \\
& GG & $11.58 \%$ & $0.00 \%$ & \\
& AG & $41.05 \%$ & $41.03 \%$ & \\
& A allele & $32.11 \%$ & $20.51 \%$ & 0.07 \\
& G allele & $67.89 \%$ & $79.49 \%$ & \\
\hline
\end{tabular}

MeDIP-qPCR was performed. The procedure includes three steps ${ }^{34}$ : (1) sonication of gDNA $(20 \mu \mathrm{g})$; (2) immunoprecipitation of the sonicated and denatured gDNA ( 5 $\mu \mathrm{g})$; this step was performed overnight at $4{ }^{\circ} \mathrm{C}$ using $5 \mu \mathrm{l}$ of a monoclonal antibody against $5 \mathrm{mC}$ (anti-5-methylcytosine, 5-mC, mouse monoclonal antibody (catalog \#33D3, Millipore), $50 \mu \mathrm{IP}$ Buffer (10 mm sodium phosphate ( $\mathrm{pH}$ $7.0), 140 \mathrm{~mm} \mathrm{NaCl}, 0.05 \%$ Triton X-100), in a final volume of $500 \mu \mathrm{TE}$; incubated the mixture with $80 \mu \mathrm{l}$ of Dynabeads (Life Technologies) overnight at $4{ }^{\circ} \mathrm{C}$ and washed it three times with $700 \mu \mathrm{l}$ of IP buffer. The beads were then treated with proteinase $\mathrm{K}$ for $3 \mathrm{~h}$ at $50^{\circ} \mathrm{C}$ and recovered the methylated DNA by phenol-chloroform extraction followed by ethanol precipitation. Sheared "input" DNA samples were collected prior to immunoprecipitation for subsequent comparison with immunoprecipitated DNA (3) quantitative real-time PCR using specific ChIP primers to determine the DNA methylation enrichment. Primers were designed using BLAST Pick up Primer Tool; the CpG regions position was investigated using UCSC genome browser (on Human Dec. 2013 (GRCh38/hg38) Assembly; https://genome.ucsc.edu/cgi-bin/hgGateway). The specific primer sequences used in this study are listed in Fig. 2a and all the details on primer sites annealing are reported in the Supplementary material section.

\section{Statistical analyses}

Fisher's exact test was applied to examine the relationship between both allele frequencies and genotypic distribution with CU.

Haplotype frequencies, haplotype odds ratio and 95\% confidence interval, and pairwise linkage disequilibrium were estimated. Haplotype frequencies were determined by using PLINK (1.07, Author: Shaun Purcell, URL: http:// pngu.mgh.harvard.edu/purcell/plink/). The SNPs involved in haplotypes analysis (Table $2 \mathrm{C}$ ) were the six SNPs of CNR1 on chromosome 6 (rs1049353|rs806379| rs6454674|rs2023239|rs12720071|rs2180619). 
Table 2C Haplotype analysis of the six SNPs of CNR1. Positive associations at the 2-4 SNPs levels are reported

\begin{tabular}{|c|c|c|c|c|c|c|c|}
\hline $\begin{array}{l}\text { Sliding } \\
\text { window }\end{array}$ & SNPS forming the haplotype & Haplo-type & Frequency in $\mathrm{MJ}$ & Frequency in CTRLs & $\begin{array}{l}\text { Test for association } \\
\text { CHISQ }\end{array}$ & DF & $p$-value \\
\hline \multirow[t]{2}{*}{$2 \mathrm{SNPS}$} & rs12720071|rs1049353 & $\Pi$ & 0.009868 & 0.08497 & 5.279 & 1 & 0.02159 \\
\hline & rs1049353|rs2023239 & $\pi$ & 0.00692 & 0.09218 & 6.402 & 1 & 0.0114 \\
\hline \multirow[t]{2}{*}{3 SNPs } & rs12720071|rs104935| rs2023239 & $\pi$ & 0.004799 & 0.0684 & 4.721 & 1 & 0.02979 \\
\hline & rs1049353|rs2023239| rs806379 & $\Pi \mathrm{TA}$ & 0.008201 & 0.09034 & 6.019 & 1 & 0.01415 \\
\hline \multirow[t]{3}{*}{4 SNPS } & $\begin{array}{l}\text { rs12720071|rs1049353| } \\
\text { rs2023239|rs806379 }\end{array}$ & $\pi T A$ & 0.006228 & 0.07111 & 4.705 & 1 & 0.03007 \\
\hline & $\begin{array}{l}\text { rs1049353|rs2023239| rs806379| } \\
\text { rs6454674 }\end{array}$ & TTAT & 0.009029 & 0.07984 & 4.907 & 1 & 0.02674 \\
\hline & $\begin{array}{l}\text { rs1049353|rs2023239| rs806379| } \\
\text { rs6454674 }\end{array}$ & $\mathrm{CCTT}$ & 0.3776 & 0.2373 & 5.339 & 1 & 0.02086 \\
\hline
\end{tabular}

Logistic regression models were used as main statistical tool to evaluate the role of potential explanatory factors (gender, marital status (married vs unmarried), educational attainment (1. Some high school/GED, 2. High school diploma, 3. Some college, 4. College Graduate, Masters, Ph.D.)), BMI, on the risk of CU. Two nested models were estimated. The first model is aimed to assess the potential influence of socio-demographic variables on $\mathrm{CU}$, while a second model also included genotyping data. Because of the different gender composition of the two groups, it is considered appropriate to insert gender in the logistic regression models to evaluate its potential confounding effect.

MeDIP-qPCR statistical analysis was performed using STATVIEW 5.0. All the quantitative data are presented as mean + SEM. For data comparing controls (CTRL) and cannabis users (MJ) groups, unpaired Student's $t$-test was used (StatView version 5.01, St. Louis, Missouri).

In addition, to identify a possible interaction between DNA methylation and respectively the SNP rs1049353 and the SNP rs1800497 (the only two variants for which it was possible to design MeDIP primers). Student's $t$-test for independent samples was run.

For all the statistical analyses, results were considered statistically significant at $p \leq 0.05$.

\section{Results}

\section{Socio-demographic findings}

In the first logistic regression model (Table 3A), evaluating the influence of socio-demographic factors on $\mathrm{CU}$, gender was found to significantly contribute to $\mathrm{CU}$ risk. Male participants had 6.6 times higher risk to be cannabis users compared to females $(p=0.001)$. In addition, all the levels of educational attainment higher than the reference category seem to decrease the risk of CU. The highest level of education, College Graduate/Masters/Ph.D., reduced significantly the risk by $90 \%(p=0.006)$. Both marital status and BMI did not show any statistical relation with CU.

\section{Genetic findings}

$G$ allele and homozygous GG genotype of SNP rs1049353 (G1539A) (CNR1 gene) were significantly higher among cannabis users compared to control subjects (respectively $p=0.002 ; p=0.01$ ) (Table $2 \mathrm{~B}$ ). Even excluding homozygous A/A subjects, due to the low number of observations ( $0 \%$ among cannabis users and $4.2 \%$ among controls), the differences were confirmed ( $p$ $=0.02)$. Differences were observed $(p=0.058)$ for the SNP rs2501431 of the CNR2 gene. There were no statistical significant differences in the SNP Taq1A (ANKK1) or CNR1 gene (rs806379, rs6454674, rs2023239, rs12720071, rs2180619) (Table 2B).

The haplotype analysis for the six CNR1 SNPs located on chromosome 6 (rs1049353|rs806379|rs6454674| rs2023239|rs12720071|rs2180619) revealed positive associations for the 2-4 SNPs levels reported in Table $2 \mathrm{C}$.

\section{Gene-sociodemographic interactions}

A second logistic regression model (Table 3B) tested simultaneously the influence of genetic and environmental risk factors considering the concurrent influence on $\mathrm{CU}$ of the previous significant parameters: the genetic variables rs1049353 (CNR1) and rs2501431 (CNR2), gender and educational attainment. Gender $(p<0.05)$, and the educational attainment $(p=0.002)$ were confirmed to have a significant relation with CU. G allele of rs1049353 (CNR1) was confirmed to confer a higher risk to be cannabis users $(p=0.05)$.

\section{Epigenetic findings}

We analyzed DNA methylation status in seven sites of ANNK1, CNR1, DRD2 and NCAM1 genes, listed in Fig. 2a 


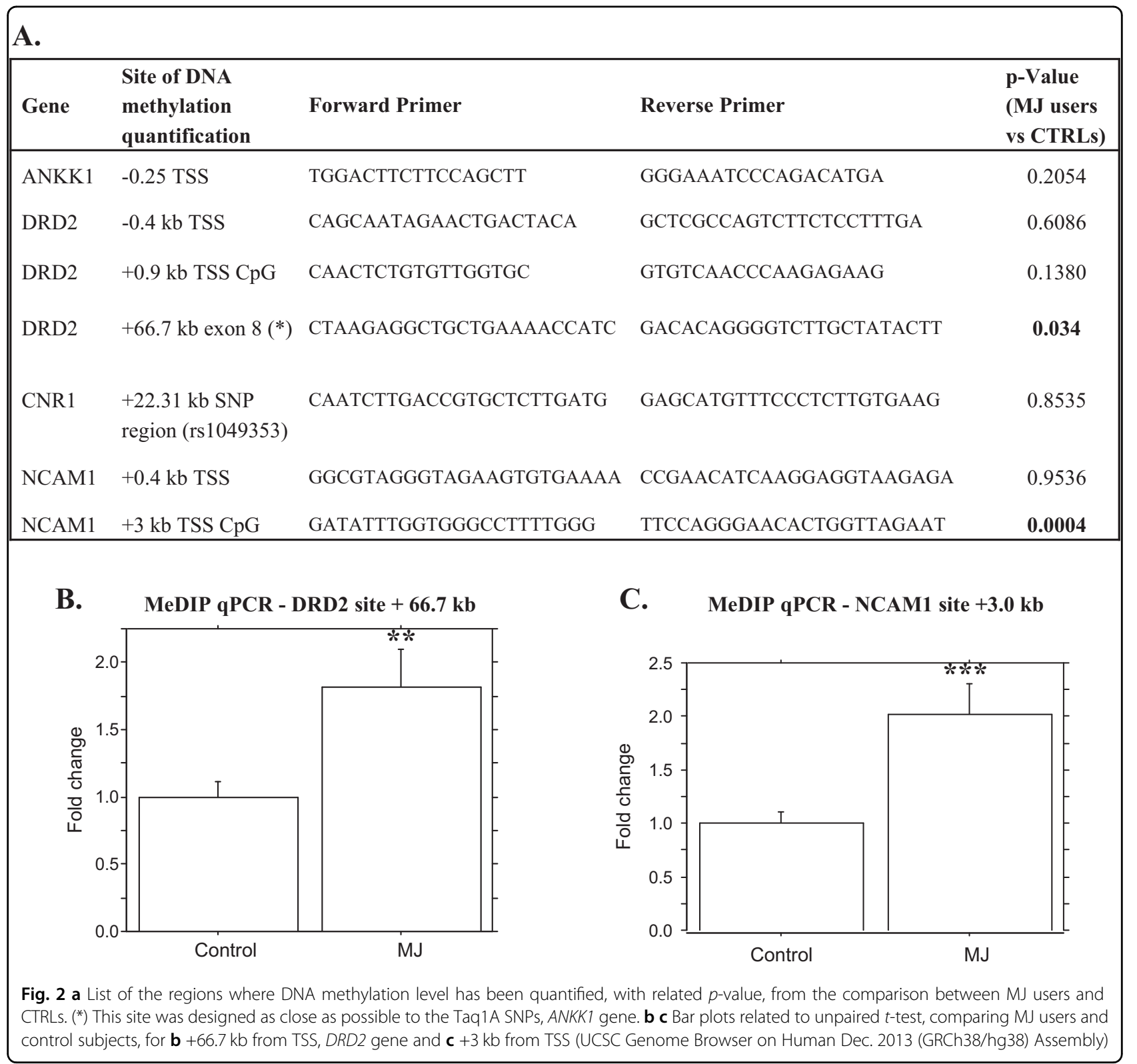

and related to CU. DNA methylation was significantly higher in cannabis users compared to control subjects in two of the regions analyzed (Fig. 2b, c). The first site was in the exon 8 of DRD2 gene at $+66.7 \mathrm{~kb}$ from the TSS (see Figure $4 S)(p=0.034)$ and the second was located on a CpG region at $+3 \mathrm{~kb}$ from the TSS (Figure 6S) in the NCAM1 gene $(p=0.0004)$. No differences in DNA methylation were found at $A N K K 1-0.25 \mathrm{~kb}, D R D 2-0.4 \mathrm{~kb}$ and $+0.9 \mathrm{~kb}$, NCAM1 $+0.4 \mathrm{~kb}$, CNR1 +22.31 kb, comparing cannabis users and control subjects (Figs. 1S-3S, 5S, 7S).

\section{Discussion}

The main findings of our study are: (1) SNP rs1049353 in CNR1 gene is associated with CU; (2) the highest level of education, College graduate/Masters/Ph.D., reduced significantly the risk to be cannabis users; and (3) changes in DNA methylation, comparing cannabis users and control, were observed in two sites related to DRD2 and NCAM1 genes.

Our findings are consistent with the nominal association found between the G allele, SNP rs1049353, and cannabis dependence symptoms ${ }^{10}$. The SNP rs1049353 polymorphism appears to play a significant role in the function of cannabinoid receptor by influencing mRNA translation as well as secondary structure and stability of the protein ${ }^{35,36}$. Thus, it is possible that individuals who carry this SNP might experience different marijuanainduced behavioral or physiological effects and may also 
Table 3A Variable(s) entered on step 1: gender, marital status (married (ref cat)-unmarried), BMI, education (4 categories)

\begin{tabular}{lllllll} 
Variables in the equation & & & & & & \\
\hline & B & S.E. & Wald & df & Sig. & Exp(B) \\
\hline $\begin{array}{l}\text { Gender, female (ref cat), } \\
\text { male }\end{array}$ & 1.889 & 0.505 & 14.006 & 1 & $\mathbf{0 . 0 0 0}$ & 6.615 \\
Marital status, married (ref & 1.168 & 0.919 & 1.615 & 1 & 0.204 & 3.216 \\
cat), unmarried & & & & & & \\
BMl & 0.024 & 0.031 & .610 & 1 & 0.435 & 1.024 \\
$\begin{array}{l}\text { 1-Some high school/2-GED } \\
\text { (ref cat) }\end{array}$ & & & & & & \\
3-H.S. diploma (1) & -1.088 & 0.618 & 3.095 & 1 & 0.079 & 0.337 \\
4-Some college (2) & -0.354 & 0.581 & .370 & 1 & 0.543 & 0.702 \\
5-College-graduate/6- & -2.436 & 0.883 & 7.621 & 1 & $\mathbf{0 . 0 0 6}$ & 0.087 \\
Masters/7-Ph.D (3) & & & & & & \\
Constant & -3.001 & 1.488 & 4.068 & 1 & 0.044 & 0.050 \\
\hline
\end{tabular}

Significant contributions are indicated as bold values

show different phenotypes that are regulated by the cannabinoid system ${ }^{10,37-40}$. These suggestions might explain why the $\mathrm{G}$ allele may serve as a risk factor for $\mathrm{CU}^{41}$.

To increase the power to detect genetic traits associated with $\mathrm{CU}$, haplotype-based association analysis was also used. Different combinations of SNPs in CNR1 showed significant associations with $\mathrm{CU}$ at 2-4 SNPs levels for seven haplotypes in our study. These observations are consistent with another research group that had reported a significant association of CNR1 haplotype rs806368rs1049353-rs2023239-rs6454674 with the level of cannabis exposure and decreased volume of the right anterior cingulum $^{42}$.

For the variant rs2501431 in the other cannabinoid receptor CNR2 gene, differences were observed in genotype distribution, with the homozygous A/A genotype being more frequent in the cannabis group. When we excluded GG genotypes, the association did not reach significant values $(p=0.7)$, leading us to assume a very important role of the $\mathrm{G}$ allele. This statement is consistent with the report that the GG genotype is associated with alcoholism in a Japanese population ${ }^{43}$. Together, these observations suggest the need for further study to elucidate the role of rs2501431 in CNR2 gene as possible risk factor of $\mathrm{CU}$ and other addiction diagnoses.

In addition, our data highlight the importance of gender in CU susceptibility. Compared to females, male subjects in the study presented a significantly higher risk to use cannabis. These findings underlie the importance of better exploring gender difference in addiction research. Gender differences in CU are indeed frequently reported,
Table 3B Variable(s) entered on step 2: gender, education (4 categories) rs1049353, A allele (ref cat)-G allele, rs25GA43A, G allele (ref cat)-A allele

\begin{tabular}{lcccccc} 
Variables in the equation & \multicolumn{1}{l}{} & & & & \\
\hline & B & S.E. & Wald & df & Sig. & Exp(B) \\
\hline $\begin{array}{l}\text { Gender, female (ref cat), } \\
\text { male }\end{array}$ & 2.054 & 0.514 & 15.951 & 1 & $\mathbf{0 . 0 0 0}$ & 7.797 \\
1-Some high school/2-GED (ref cat) & & & & & \\
3-H.S. diploma (1) & -1.374 & 0.709 & 3.757 & 1 & 0.053 & 0.253 \\
4-Some college (2) & -.542 & 0.623 & .757 & 1 & 0.384 & 0.582 \\
5-College graduate/6- & -2.851 & 0.926 & 9.491 & 1 & $\mathbf{0 . 0 0 2}$ & 0.058 \\
Masters/7-Ph.D (3) & & & & & & \\
rs1049353, A allele (ref cat) & 3.161 & 1.116 & 8.024 & 1 & 0.005 & 23.584 \\
G allele & & & & & & \\
rs25GA43A, G allele (ref cat) & -.183 & 0.503 & .133 & 1 & 0.716 & 0.833 \\
A allele & & & & & & \\
Constant & -3.854 & 1.179 & 10.683 & 1 & 0.001 & 0.021 \\
\hline
\end{tabular}

Significant contributions are indicated as bold values

with male proneness to use the drug more frequently or at a higher rate than females ${ }^{44-46}$. Gender-based differences in cannabinoid effects have been evidenced by preliminary studies investigating the role of gonadal hormones in the regulation of cannabis receptors density and affinity ${ }^{47}$. Other studies highlighted that sex differences could also be influenced by drug disposition and body fat distribu$\operatorname{tion}^{48}$. However, the fact that females are underrepresented in our study and others may also lead to incomplete and biased results.

Importantly, the evaluation of sociodemographic risk factors helped to confirm that higher education attainment might serve as a possible protective factor, considering the significant inverse relation between education levels and CU. A previous study had reported that users with higher education do not suffer from cognitive deficits with chronic abuse of cannabis ${ }^{49}$. Interestingly, strong engagement in school and good school achievements have also been repeatedly reported to be important resilience factors against substance use disorders ${ }^{50-54}$. Thus, poor school performance and dropping out of schools may not only be risk factors for substance use disorders but may be the consequences of shared genetic/epigenetic risks that predict both school failure and $\mathrm{CU}$ initiation ${ }^{55,56}$. The potential impact of cannabis on school performance is also very important to consider ${ }^{57-60}$. Logistic regression analysis demonstrated that both genetic (rs1049353, CNR1 gene) and sociodemographic risk factors are coincident, representing endophenotypes associated with $\mathrm{CU}$ risks. The role of endophenotypes for the rational development of therapeutic and preventive strategies has 


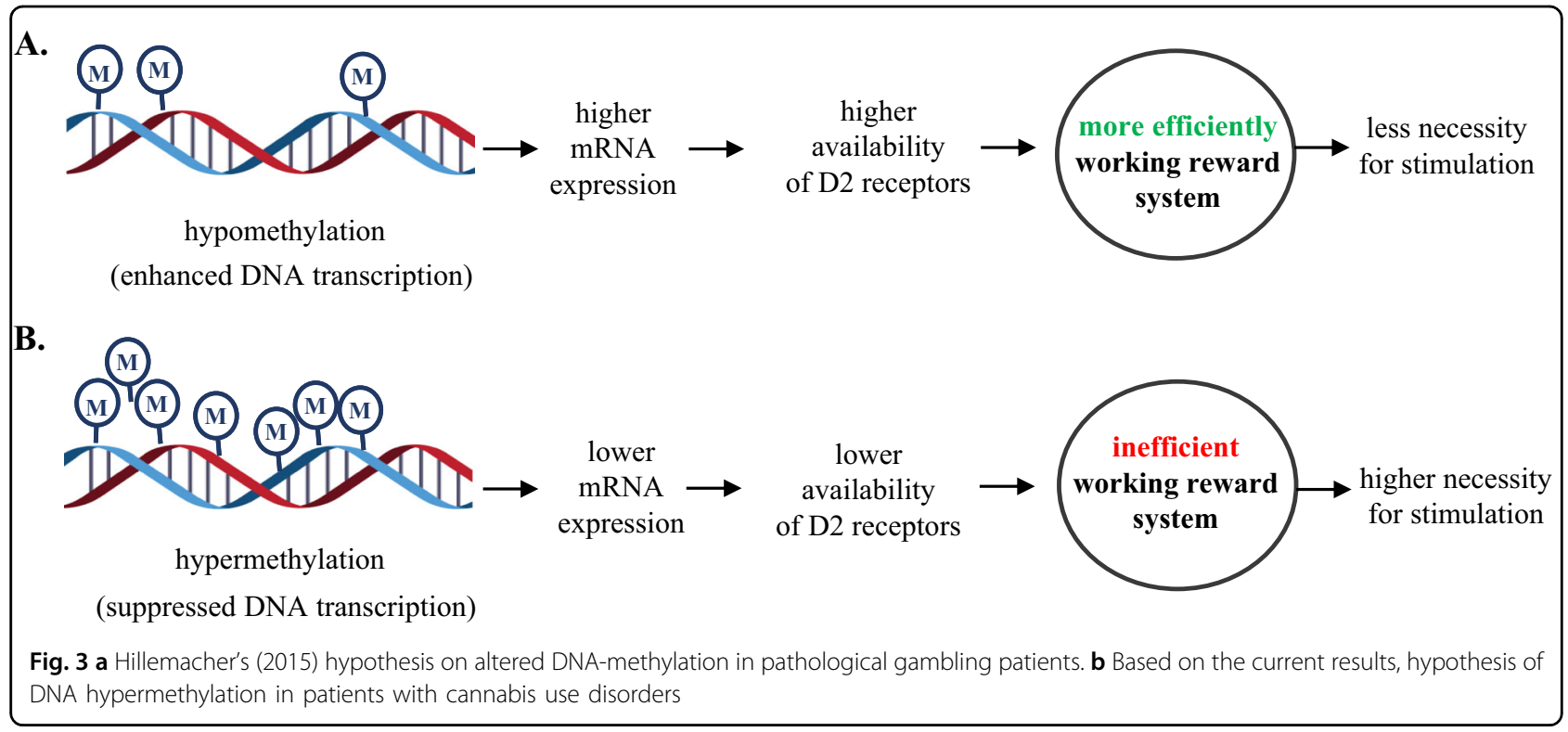

previously been assessed and suggests that these are important variables in treatment approaches ${ }^{61}$.

Our epigenetic findings also appear to suggest that not only inherited gene variants, but also changes in gene expression could be associated to CU. Hypermethylation was reported in cannabis users compared to controls at DRD2 exon 8 and in a CpG-rich region of the NCAM1 gene. The observed NCAM1 differentially methylated region (DMR) was located on the $5^{\prime} \mathrm{CpG}$ island of the gene and promoter-associated DMR-CpGs are usually shown to cause transcriptional silencing ${ }^{62}$. Even if the functional significance of DNA methylation in introns, exons, and intergenic intervals is still less wellunderstood $^{63,64}$, the DRD2 DMR, located within the exon 8 , suggests the importance of these gene body sites, as already shown in a study on parental THC exposure $^{65}$.

Both genes, DRD2 and NCAM1 have a central role in the dopaminergic pathway ${ }^{66}$ and have been recently found significantly associated with lifetime $\mathrm{CU}^{16}$. They are part of the NCAM1-TTC12-ANKK1-DRD2 gene cluster (NTAD), suggested to be associated to nicotine dependence $^{67}$ and other substance use disorders in general ${ }^{68}$.

Other behavioral conditions were reported to be associated with DNA methylation in these two genes. DRD2 promoter showed highest methylation levels in patients with gambling behavior, compared to non-gambling participants and, because DNA-hypermethylation is usually associated with transcriptional repression, the subsequently higher availability of D2 receptor was assumed to result in a more active working of the reward system $^{69}$.

Based on these evidences, we could hypothesize (Fig. 3) that increased DNA methylation observed in cannabis users' blood cells may in some way reflect a lower D2 mRNA expression, lower availability of D2 receptors underlying a reward deficit condition. This difference in the reward system function related to methylation may lead to a reduced need for reinforcing stimuli in noncannabis users, and a higher necessity of pharmacological stimulation in cannabis-dependent subjects.

The observed hypermethylation in NCAM1 gene is consistent with the hypermethylated $\mathrm{CpG}$ regions of NCAM1 in alcohol-dependent patients compared with controls $^{70,71}$. This gene that was previously found significantly associated with lifetime $\mathrm{CU}^{16}$ encodes a neural cell adhesion molecule implicated in important functions during development and maintenance of the nervous system. A study in rodents proposed NCAM as a modulator of the dopaminergic pathway and a potential pharmacological target for dopamine-related psychiatric disorders ${ }^{72}$.

In the interpretation of our findings concerning hypermethylation in cannabis users, it is impossible to establish any causal relationship. Epigenetic changes affecting DRD2 and NCAM1 could be the result of longterm exposure to cannabis and not a pre-existing condition involved in $\mathrm{CU}$ neurobiological vulnerability.

The present study has certain limitations. First, because the number of cannabis users was relatively low, statistical power was not as strong as expected. Moreover, since polymorphisms may vary in frequency among different ethnic groups ${ }^{73}$, it might have been more appropriate to split the samples based on ethnic groups. However, this was not possible due to the relatively small number of subjects per group. The results obtained by the present study could thus be attributed to the ethno-racial background of the participants. Thus, any extension to other 
ethnic groups should be done with caution and will need to be investigated further.

Another important limitation is that most of the changes in DNA methylation patterns were observed in peripheral cells ${ }^{74}$ such as WBCs that may not reflect changes in reward brain regions. Moreover, the changes in DNA methylation patterns were investigated at a single time point, thus, precluding the possibility of examining time-dependent effects of marijuana exposure on DNA methylation. Replication studies using specific cell types and brain tissues should help to further clarify the role of DNA methylation in CUD. Another issue that needs to be investigated in future replication studies include assessment of the role of marijuana on other epigenetic markers. This will entail examining changes in histone modifications and DNA methylation during the clinical course of repeated marijuana exposure. Indeed, the use of genome-wide methylation or chromatin immunoprecipitation studies should help to identify other genes that might be involved as either risk factors or consequences of cannabis exposure.

Overall, our results suggest a significant role of genes encoding proteins involved in the endocannabinoid system in the susceptibility for CU. Our study also identified epigenetic modifications affecting dopamine system function as risk factors and/or consequences of marijuana exposure. Confirmation studies that address the shortcomings detailed above are necessary to clarify to what extent changes in peripheral DNA methylation could serve as accessible sources of biological markers and/or targets for pharmacological interventions that might reduce or prevent the effects of marijuana in the brain. Finally, because education attainment was identified as a protective factor for $\mathrm{CU}$, these observations suggest the building and expansion of early childhood educational programs and strategies to prevent CUD in adolescence and later in life.

\footnotetext{
Acknowledgements

This work was supported by funds of the Intramural Research Program (IRP) of the National Institute of Drug Abuse (DHHS/NIH/NIDA), project \#12-DA-N472, NIDA, IRP [Health Outcomes by Neighbourhood ( $\mathrm{HON}$ )—Baltimore]. The authors also acknowledge the support of Dr. Antonello Bonci, NIDA IRP Scientific Director, who made it possible for Maria Carla Gerra to work at the NIDA IRP.
}

\section{Author details}

'Department of Chemistry, Life Science and Environmental Sustainability, University of Parma, Parma, Italy. ${ }^{2}$ Molecular Neuropsychiatry Research Branch, NIDA Intramural Research Program, Baltimore, MD, USA. ${ }^{3}$ Office of the Clinical Director, NIDA Intramural Research Program, Baltimore, MD, USA

\section{Authors' contributions}

The study conception and design were by MCG, SJ, JLC, and CD. Samples for the study were kindly provided by KAP. MCG, SJ, and DW worked together in the acquisition of data including genotyping and DNA methylation assays. Data analysis, interpretation, and correlations using environmental data were performed by SJ, MCG, DW, in conjunction with the biostatisticians, MM and JS. All authors contributed to the drafting and revisions of the manuscript.
Conflict of interest

The authors declare that they have no conflict of interest.

\section{Publisher's note}

Springer Nature remains neutral with regard to jurisdictional claims in published maps and institutional affiliations.

Supplementary Information accompanies this paper at https://doi.org/ 10.1038/s41398-017-0087-1.

Received: 22 May 2017 Revised: 25 July 2017 Accepted: 21 November 2017 Published online: 22 January 2018

\section{References}

1. Anthony, J. C. The epidemiology of cannabis dependence. In Cannabis Dependence: Its Nature, Consequences and Treatment (eds Roffman, R. \& Stephens, R. S.) 58-105 (Cambridge University Press, Cambridge, UK, 2006)

2. Anthony, J. C. Steppingstone and gateway ideas: a discussion of origins, research challenges, and promising lines of research for the future. Drug. Alcohol Depend. 123(Suppl 1), S99-S104 (2012).

3. WHO (World Health Organization). Management of Substance Abuse: Cannabis (WHO, Geneva, 2016) (http://www.who.int/substance_abuse/facts/cannabis/ en/).

4. Verweij, K. J. et al. Genetic and environmental influences on cannabis use initiation and problematic use: a meta-analysis of twin studies. Addiction 105, 417-430 (2010).

5. Agrawal, A. \& Lynskey, M. T. The genetic epidemiology of cannabis use, abuse and dependence. Addiction 101, 801-812 (2006).

6. Agrawal, A., Madden, P. A., Bucholz, K. K., Heath, A. C. \& Lynskey, M. T. Initial reactions to tobacco and cannabis smoking: a twin study. Addiction 109 , 663-671 (2014).

7. Agrawal, A., Neale, M. C., Prescott, C. A. \& Kendler, K. S. A twin study of early cannabis use and subsequent use and abuse/dependence of other illicit drugs. Psychol. Med. 34, 1227-1237 (2004).

8. Nacak, M. et al. Analysis of dopamine D2 receptor (DRD2) gene polymorphisms in cannabinoid addicts. J. Forensic Sci. 57, 1621-1624 (2012).

9. Ruiz-Contreras, A. E. et al. Performance in working memory and attentional control is associated with the rs2180619 SNP in the CNR1 gene. Genes. Brain Behav. 13, 173-178 (2014).

10. Buchmann, A. F. et al. Role of CNR1 polymorphisms in moderating the effects of psychosocial adversity on impulsivity in adolescents. J. Neural Transm. 122, 455-463 (2015).

11. Ho, B. C., Wassink, T. H., Ziebell, S. \& Andreasen, N. C. Cannabinoid receptor 1 gene polymorphisms and marijuana misuse interactions on white matter and cognitive deficits in schizophrenia. Schizophr. Res. 128, 66-75 (2011).

12. Mitjans, M., Gastó, C., Catalán, R., Fañanás, L. \& Arias, B. Genetic variability in the endocannabinoid system and 12-week clinical response to citalopram treatment: the role of the CNR1, CNR2 and FAAH genes. J. Psychopharmacol. 26, 1391-1398 (2012).

13. Lester, K. J. et al. Genetic variation in the endocannabinoid system and response to Cognitive Behavior Therapy for child anxiety disorders. Am. J. Med. Genet. B Neuropsychiatr. Genet. 174, 144-155 (2017).

14. Agrawal, A. et al. A genome-wide association study of DSM-IV cannabis dependence. Addict. Biol. 16, 514-518 (2011).

15. Sherva, R. et al. Genome-wide association study of cannabis dependence severity, novel risk variants, and shared genetic risks. JAMA Psychiatry 73, 472-480 (2016).

16. Stringer, S. et al. Genome-wide association study of lifetime cannabis use based on a large meta-analytic sample of 32330 subjects from the International Cannabis Consortium. Transl. Psychiatry 6, e769 (2016).

17. Gizer I. R., Bizon C., Gilder D. A., Ehlers C. L. \& Wilhelmsen K. C. Whole genome sequence study of cannabis dependence in two independent cohorts. Addict. Biol. 2017, https://doi.org/10.1111/adb.12489 [Epub ahead of print].

18. Agrawal, A et al. DSM-5 cannabis use disorder: a phenotypic and genomic perspective. Drug. Alcohol Depend. 134, 362-369 (2014).

19. Suerken, C. K. et al. Marijuana use trajectories and academic outcomes among college students. Drug. Alcohol Depend. 162, 137-145 (2016). 
20. Silins, E. et al. Cannabis Cohorts Research Consortium. Adolescent substance use and educational attainment: an integrative data analysis comparing cannabis and alcohol from three Australasian cohorts. Drug. Alcohol Depend. 156, 90-96 (2015)

21. Stiby, A. I. et al. Adolescent cannabis and tobacco use and educational outcomes at age 16: birth cohort study. Addiction 110, 658-668 (2015).

22. van Ours, J. C. \& Williams, J. Why parents worry: initiation into cannabis use by youth and their educational attainment. J. Health Econ. 28, 132-142 (2009).

23. Harrison, P. A., Fulkerson, J. A. \& Beebe, T. J. Multiple substance use among adolescent physical and sexual abuse victims. Child. Abus. Negl. 21, 529-539 (1997).

24. Kilpatrick, D. G. et al. Risk factors for adolescent substance abuse and dependence: data from a national sample. J. Consult. Clin. Psychol. 68, 19-30 (2000).

25. Rotter, A. et al. CB1 and CB2 receptor expression and promoter methylation in patients with cannabis dependence. Eur. Addict. Res. 19, 13-20 (2013).

26. van der Knaap, L. J. et al. Catechol-O-methyltransferase gene methylation and substance use in adolescents: the TRAlLS study. Genes. Brain Behav. 13, 618-625 (2014).

27. DiNieri, J. A. et al. Maternal cannabis use alters ventral striatal dopamine D2 gene regulation in the offspring. Biol. Psychiatry 70, 763-769 (2011).

28. Tomasiewicz, H. C. et al. Proenkephalin mediates the enduring effects of adolescent cannabis exposure associated with adult opiate vulnerability. Biol. Psychiatry 72, 803-810 (2012).

29. Paradisi, A., Pasquariello, N., Barcaroli, D. \& Maccarrone, M. Anandamide regulates keratinocyte differentiation by inducing DNA methylation in a CB1 receptor-dependent manner. J. Biol. Chem. 283, 6005-6012 (2008).

30. Cecil, C. A. et al. DNA methylation and substance-use risk: a prospective, genome-wide study spanning gestation to adolescence. Transl. Psychiatry $\mathbf{6}$ e976 (2016)

31. Gutierrez-Arcelus, M. et al. Passive and active DNA methylation and the interplay with genetic variation in gene regulation. Elife 2, e00523 (2013).

32. Jones, M. J., Fejes, A. P. \& Kobor, M. S. DNA methylation, genotype and gene expression: who is driving and who is along for the ride? Genome Biol. 14, 126 (2013).

33. Vidot, D. C., Bispo, J. B., Hlaing, W. M., Prado, G. \& Messiah, S. E. Moderate and vigorous physical activity patterns among marijuana users: results from the 2007-2014 National Health and Nutrition Examination Surveys. Drug. Alcohol Depend. 178, 43-48 (2017).

34. Weber, M. et al. Chromosome-wide and promoter-specific analyses identify sites of differential DNA methylation in normal and transformed human cells. Nat. Genet. 37, 853-862 (2005).

35. Shen, L. X., Basilion, J. P. \& Stanton, V. P. Jr. Single-nucleotide polymorphisms can cause different structural folds of mRNA. Proc. Natl. Acad. Sci. USA 96 7871-7876 (1999)

36. Chakrabarti, B., Kent, L., Suckling, J., Bullmore, E. \& Baron-Cohen, S. Variations in the human cannabinoid receptor (CNR1) gene modulate striatal responses to happy faces. Eur. J. Neurosci. 23, 1944-1948 (2006).

37. Dinu, I. R., Popa, S., Bîcu, M., Mota, E. \& Mota, M. The implication of CNR1 gene's polymorphisms in the modulation of endocannabinoid system effects. Rom. J. Intern. Med. 47, 9-18 (2009).

38. Hill, M. N. \& Patel, S. Translational evidence for the involvement of the endocannabinoid system in stress-related psychiatric illnesses. Biol. Mood Anxiety Disord. 3, 19 (2013).

39. Agrawal, A. et al. Cannabinoid receptor genotype moderation of the effects of childhood physical abuse on anhedonia and depression. Arch. Gen. Psychiatry 69, 732-740 (2012).

40. Hopfer, C. J. et al. Cannabis receptor haplotype associated with fewer cannabis dependence symptoms in adolescents. Am. J. Med. Genet. B Neuropsychiatr. Genet. 141B, 895-901 (2006).

41. Hartman, C. A. et al. The association between cannabinoid receptor 1 gene (CNR1) and cannabis dependence symptoms in adolescents and young adults. Drug. Alcohol Depend. 104, 11-16 (2009).

42. Hill, S. Y., Sharma, V. \& Jones, B. L. Lifetime use of cannabis from longitudinal assessments, cannabinoid receptor (CNR1) variation, and reduced volume of the right anterior cingulate. Psychiatry Res. 255, 24-34 (2016).

43. Ishiguro, $H$. et al. Involvement of cannabinoid CB2 receptor in alcohol preference in mice and alcoholism in humans. Pharm. J. 7, 380-385 (2007).

44. Agrawal, A. \& Lynskey, M. T. Does gender contribute to heterogeneity in criteria for cannabis abuse and dependence? Results from the nationa epidemiological survey on alcohol and related conditions. Drug. Alcohol Depend. 88, 300-307 (2007).

45. Perkonigg, A. et al. The natural course of cannabis use, abuse and dependence during the first decades of life. Addiction 103, 439-449 (2008).

46. Farmer, R. F. et al. Internalizing and externalizing psychopathology as predictors of cannabis use disorder onset during adolescence and early adulthood. Psychol. Addict. Behav. 29, 541-551 (2015)

47. Gorzalka, B. B. \& Dang, S. S. Endocannabinoids and gonadal hormones: bidirectional interactions in physiology and behaviour. Endocrinology 153, 1016-1024 (2012)

48. Fattore, L. \& Fratta, W. How important are sex differences in cannabinoid action? Br. J. Pharmacol. 160, 544-548 (2010).

49. Bolla, K. I., Brown, K., Eldreth, D., Tate, K. \& Cadet, J. L. Dose-related neurocognitive effects of marijuana use. Neurology 59, 1337-1343 (2002).

50. Hodder, R. K. et al. A school-based resilience intervention to decrease tobacco, alcohol and marijuana use in high school students. BMC Public Health 11, 722 (2011).

51. Council on School Health, American Academy of Pediatrics; Committee on Substance Abuse, American Academy of Pediatrics, Mears, C. J. \& Knight, J. R. The role of schools in combating illicit substance abuse. Pediatrics $\mathbf{1 2 0}$, 1379-1384 (2007)

52. Skinner, M. L., Haggerty, K. P. Fleming, C. B. \& Catalano, R. F. Predicting functional resilience among young-adult children of opiate-dependent parents. J. Adolesc. Health 44, 283-290 (2009).

53. Napoli, M., Marsiglia, F. F. \& Kulis, S. Sense of belonging in school as a protective factor against drug abuse among native American urban adolescents. J. Soc. Work. Pract. Addict. 3, 25-41 (2003).

54. Lynskey, M. \& Hall, W. The effects of adolescent cannabis use on educational attainment: a review. Addiction 95, 1621-1630 (2000).

55. Kelly, A. B. et al. A longitudinal study of the association of adolescent polydrug use, alcohol use and high school non-completion. Addiction 110, 627-635 (2015).

56. Verweij, K. J., Huizink, A. C., Agrawal, A., Martin, N. G. \& Lynskey, M. T. Is the relationship between early-onset cannabis use and educational attainment causal or due to common liability? Drug. Alcohol Depend. 133, 580-586 (2013).

57. Carey, S. E., Nestor, L., Jones, J., Garavan, H. \& Hester, R. Impaired learning from errors in cannabis users: dorsal anterior cingulate cortex and hippocampus hypoactivity. Drug. Alcohol Depend. 155, 175-182 (2015).

58. Crean, R. D., Crane, N. A. \& Mason, B. J. An evidence based review of acute and long-term effects of cannabis use on executive cognitive functions. J. Addict. Med. 5, 1-8 (2011)

59. Meier, M. H. et al. Persistent cannabis users show neuropsychological decline from childhood to midlife. Proc. Natl. Acad. Sci. USA 109, E2657-E2664 (2012).

60. Volkow, N. D., Baler, R. D., Compton, W. M. \& Weiss, S. R. Adverse health effects of marijuana use. N. Engl. J. Med. 370, 2219-2227 (2014).

61. Ersche, K. D. et al. Cognitive dysfunction and anxious-impulsive personality traits are endophenotypes for drug dependence. Am. J. Psychiatry 169, 926-936 (2012).

62. Brenet, $F$. et al. DNA methylation of the first exon is tightly linked to transcriptional silencing. PLOS. ONE 6, e14524 (2011).

63. Jones, P. A. Functions of DNA methylation: islands, start sites, gene bodies and beyond. Nat. Rev. Genet. 13, 484-492 (2012).

64. Schübeler, D. Function and information content of DNA methylation. Nature 517, 321-326 (2015)

65. Watson, C. T. et al. Genome-wide DNA methylation profiling reveals epigenetic changes in the rat nucleus accumbens associated with crossgenerational effects of adolescent THC exposure. Neuropsychopharmacology 40, 2993-3005 (2015).

66. Xiao, M. F. et al. Neural cell adhesion molecule modulates dopaminergic signaling and behavior by regulating dopamine D2 receptor internalization. J. Neurosci. 29, 14752-14763 (2009).

67. Bidwell, L. C. et al. NCAM1-TTC12-ANKK1-DRD2 variants and smoking motives as intermediate phenotypes for nicotine dependence. Psychopharmacol. (Berl.) 232, 1177-1186 (2015)

68. Ma, Y., Yuan, W., Jiang, X., Cui, W. Y. \& Li, M. D. Updated findings of the association and functional studies of DRD2/ANKK1 variants with addictions. Mol. Neurobiol. 51, 281-299 (2015).

69. Hillemacher, T. et al. Alterations in DNA-methylation of the dopamine-receptor 2 gene are associated with abstinence and health care utilization in individuals with a lifetime history of pathologic gambling. Prog. Neuropsychopharmacol. Biol. Psychiatry 63, 30-34 (2015). 
70. Zhang, $\mathrm{H}$. et al. Array-based profiling of DNA methylation changes associated with alcohol dependence. Alcohol Clin. Exp. Res. 37(Suppl 1), E108-E115 (2013).

71. Barker, J. M., Zhang, Y., Wang, F., Taylor, J. R. \& Zhang, H. Ethanol-induced Htr3a promoter methylation changes in mouse blood and brain. Alcohol Clin. Exp. Res. 37(Suppl 1), E101-E107 (2013).

72. Mota, N. R., Araujo-Jnr, E. V., Paixão-Côrtes, V. R., Bortolini, M. C. \& Bau, C. H. Linking dopamine neurotransmission and neurogenesis: The evolutionary history of the NTAD (NCAM1-TTC12-ANKK1-DRD2) gene cluster. Genet. Mol. Biol. 35, 912-918 (2012).

73. Jorde, L. B. \& Wooding, S. P. Genetic variation, classification and 'race'. Nat. Genet. 36(11 Suppl), S28-S33 (2004).

74. Terry, M. B., Delgado-Cruzata, L., Vin-Raviv, N., Wu, H. C. \& Santella, R. M. DNA methylation in white blood cells: association with risk factors in epidemiologic studies. Epigenetics 6, 828-837 (2011). 